\title{
Maturity Assessment of Laser Powder Bed Fusion Process Chain Modelling and Simulation
}

\author{
Anas Yaghi ${ }^{1}$, Shukri Afazov ${ }^{2 *}$, Matteo Villa $^{3}$ \\ ${ }^{1}$ The Manufacturing Technology Centre (MTC), Coventry CV7 9JU, UK \\ ${ }^{2}$ Department of Engineering, Nottingham Trent University, Nottingham, NG11 8NS, UK \\ ${ }^{3}$ Italian Institute of Technology, Genova16163, Italy \\ E-mail: shukri.afazov@ntu.ac.uk
}

Received: 26 February 2021; Revised: 29 June 2021; Accepted: 22 July 2021

\begin{abstract}
This paper presents case studies of additive manufacturing process chains including laser powder bed fusion and post-processes. The presented case studies are used to assess the maturity of the manufacturing process chains using a Modelling and Simulation Readiness Level Scale. The results from the assessment have shown that the maturity of the modelling and simulation of laser powder bed fusion process chains lies between the stage of applied research and development and the stage of being instrumental, with high reliance on modelling and simulation experts. This means that the laser powder bed fusion (L-PBF) process chain modelling and simulation can support low-risk development, with high reliance on modelling and simulation experts, making them suitable for qualitative assessment, alternative design/solution ranking, defining the design structure, constraining the design space and replacing some experimental trials. This shows that further maturation is required before the modelling and simulation methods and codes are well recognised as best practice in the industry and are part of operational process control at any stage of the supply chain.
\end{abstract}

Keywords: laser powder bed fusion, process chains, modelling and simulation readiness level, residual stresses, distortion mitigation

\section{Introduction}

Additive manufacturing (AM) has attracted lots of research attention among the research community. It is radically different from the conventional processes for its drastic reduction in material wastage and the ability to introduce internal design complexities that would otherwise be too challenging or even impossible to be included by the conventional manufacturing processes. However, it involves advanced manufacturing technologies that remain costly compared to conventional manufacturing processes. It also has its own challenges in relation to producing the consistent quality desired or sometimes necessary in high-value manufacturing (HVM) sectors, such as the aerospace industry.

The process that was used in this paper is laser-based powder bed fusion (L-PBF), which is a particular type of AM. This technology includes metal powder processing and extreme thermal cycles, both of which introduce technical difficulties that may compromise the quality of HVM components. Metal powder conditions, such as grain size and distribution, significantly influence the quality of the metal in the finished product [1]. Thermal cycles on the other hand induce distortion and residual stresses that can affect the quality and performance of the L-PBF part [2]. This is further

Copyright (C2021 Shukri Afazov, et al.

DOI: https://doi.org/10.37256/dmt.112021822

This is an open-access article distributed under a CC BY license

(Creative Commons Attribution 4.0 International License)

https://creativecommons.org/licenses/by/4.0/ 
influenced by any subsequent post-machining to the final shape and size, which in turn further affects distortion and residual stresses.

Distortion and residual stresses may need to be controlled or mitigated to achieve required specifications or product quality. Distortion may be compensated for at the design stage through modelling and simulation. Residual stresses can be mitigated or manipulated through post-process thermal stress relaxation or mechanical surface finish such as laser shock peening (LSP) or shot peening (SP) [3].

The modelling and simulation of the above processes and techniques usually produce valuable information that can greatly assist to control and improve the final quality of L-PBF components. Assessing the maturity of the applied modelling and simulation methods can help to decide when and how such an application is performed. The Manufacturing Technology Centre (MTC) has developed a tool for this purpose within the SimReady project [4]; the tool is called the Modelling and Simulation Readiness Level (MSRL) Scale, and it is originally derived from other scales already used in industry, such as the Technology Readiness Level (TRL) Scale that was devised by NASA. The MSRL Scale can inform decision-makers about the potential, practicality, and usefulness of applying modelling and simulation to improve L-PBF parts' quality.

In general, L-PBF can be simulated with the finite element (FE) method using different finite element techniques, for instance, the inherent strain method [5], an analytical temperature field [6], "lumping" of layers in order to avoid prohibitively large FE models [7], simulation of a moving heat source to predict the temperature and residual stresses at the micro-scale [8], the use of dynamic adaptive mesh refinement technique with a moving heat source [9-10]. Despite the significant improvement in simulation efficiency, the computational effort for industrial components is a challenge. The inherent strain method has substantially improved the computational efficiency of the FE model and it has been used to model the process of fusion welding of large structures [11] and L-PBF at macro-scale [12-16]. Liang et al. [17] also simulated and validated distortion in the directed energy deposition (DED).

Although the modelling and simulation of L-PBF processes have been individually reported in the literature, the collective consideration of the complete chain has just started its journey. Therefore, the motivation of this paper is first to present case studies where modelling and simulation of process chains have been demonstrated on industrial components in section 2. The presented case studies are then assessed for their maturity to inform researchers and industrialists for the maturity level in modelling and simulation of L-PBF process chains in section 3, which is the objective of this paper.

\section{Simulation of manufacturing process chains - case studies}

Although the modelling and simulation of L-PBF processes have been individually reported in the literature, the collective consideration of the complete chain has just started its journey. Therefore, the motivation of this paper is first to present case studies where modelling and simulation of process chains have been demonstrated on industrial components [18-21]. The presented case studies are then assessed for their maturity to inform researchers and industrialists for the maturity level in modelling and simulation of L-PBF process chains in section 3, which is the objective of this paper.

\subsection{Simulation of powder raking - a case study}

Raking procedures and powder properties can significantly influence the L-PBF build process and the resultant quality of the final product; they play an important role during the segregation of the powder. Particle size distribution (PSD) is one important property to be determined, while the particle shape can also have a significant impact on the performance [22]. A chart showing the relationship between powder characteristics and powder performance has been presented elsewhere [23], showing a schematic of the inter-related influence of the various characteristics on the powder performance, which in turn will affect the quality of the manufactured component. In this case study, the relationship between the mechanical properties of the end product is related to the PSD, porosity and impurity levels of the powder used.

The method selected to simulate the raking of metallic powder in L-PBF is the discrete element method (DEM), which is more computationally expensive than the continuum approach - i.e., the finite element method (FEM) or 
computational fluid dynamics (CFD) - but offers the following advantages [24]:

- It models the physics of the individual particles of the powder, allowing the user to have a better understanding of the actual powder behaviour compared to modelling a representative medium such as a viscous solid or liquid.

- Ideally, it doesn't require any calibration, if the behaviour of the powder is described accurately.

- It allows for a more straightforward validation or comparison with experiments without interpreting numerical results regarding powder segregation and the location of gaps.

- The physics captured by this approach can potentially give a full description of the phenomena involved in powder raking if the required computational power is available.

- The DEM approach has shown much higher scalability with the number of processors utilised, taking advantage of the latest available graphics processing unit (GPU) hardware.

To properly capture the behaviour of powder in numerical simulations, the following properties were measured:

- The sliding friction coefficient between powder and powder bed

- Coefficient of restitution between powder and powder bed

- Young's modulus of the particles of the powder

- PSD without considering the temperature and the flown gas

Different techniques to measure the PSD were investigated, each of them giving slightly different results, depending on the technique used to estimate the particle size. The PSD obtained by using micro computerised tomography was utilised for the numerical simulations, as it was the one obtained by scanning the full 3D shape of the particles (Figure 1), whilst other techniques were based on size estimation from 2D projections.

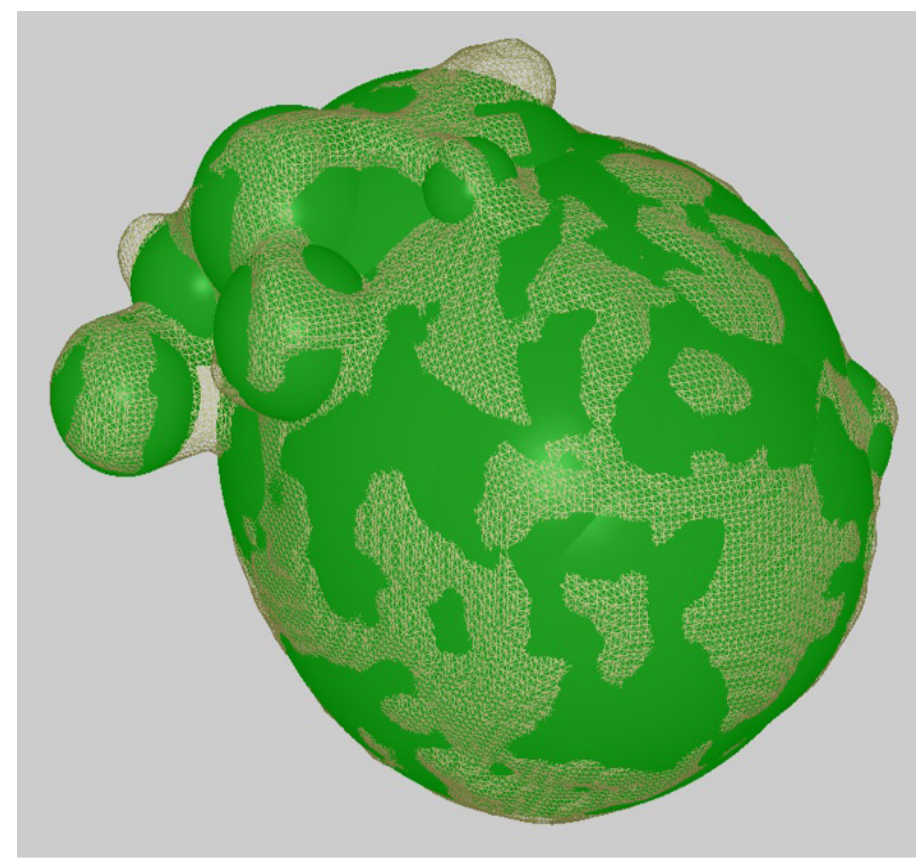

Figure 1. Example of a multi-sphere cluster for the DEM model to match the micro-CT scanned particle represented as a surface mesh (STL format)

After measuring the mentioned properties, a DEM model was generated to simulate the mechanical behaviour of the powder used for this study. The numerical model was initially validated against the hall-flow meter test, comparing results for different masses of powder.

A model to predict the behaviour of the powder during raking in L-PBF was then developed and validated against experimental measurements (Figure 2). To do so, a few layers of the powder were raked, and the PSD in different 
locations of the powder bed, around and above the L-PBF object, were analysed. Concerning the number of particles that could be sampled (i.e., one layer on top of the build and several layers around the build), different PSD techniques were used, thus giving varying results. However, experimental trends of mean size distribution were still used to successfully validate corresponding numerical mean size distribution predictions.

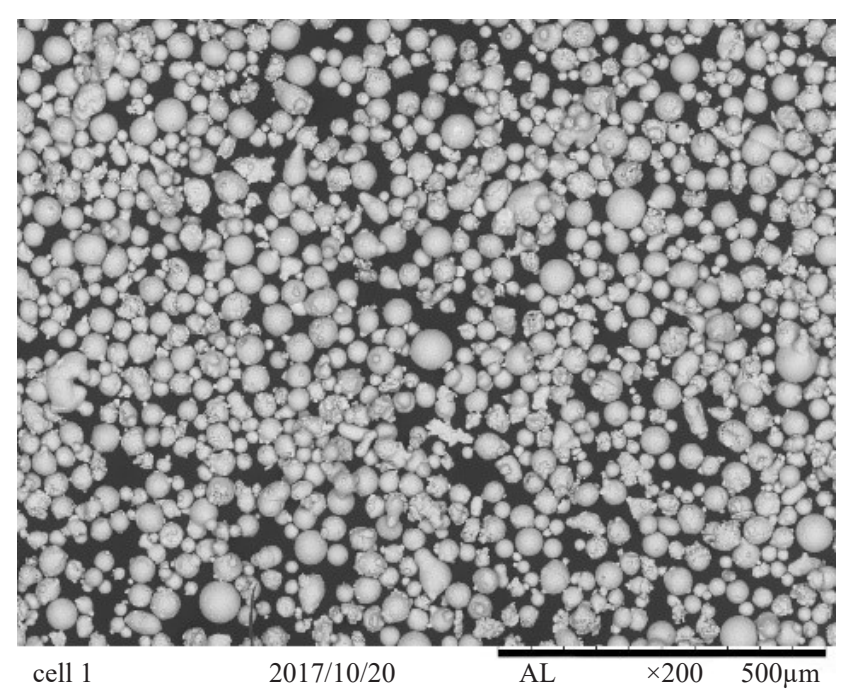

Figure 2. Example of metallic aerospace powder used by Rolls Royce sampled on a section on top of the L-PBF component

\subsection{Simulation of L-PBF process chains}

\subsubsection{A case study of an aero-casing}

A simulation of the manufacturing process chain of an aero-casing component made of Inconel 718 was presented by Afazov et al. [3]. They simulated the L-PBF using the inherent strain approach. The L-PBF model was validated based on a comparison of distortion deviations obtained by prediction and optical scanning (see Figure 3). The residual stresses and distortion from the L-PBF process have been used as an input to a heat treatment (stress relief) model. The stress relief thermal cycle simulated heating up to $980{ }^{\circ} \mathrm{C}$, remaining at that temperature for $2.5 \mathrm{~h}$, and rapid cooling down to room temperature. Temperature-dependent modulus of elasticity and yield stress have been applied for the heating and cooling steps. The holding step has been modelled by applying a creep model. The simulation of SP and LSP has been performed at a micro-scale, where the stress profiles have been predicted and compared against experimentally measured residual stresses. The stress profiles, including the stress profiles for the three direct and three shear stresses, have been mapped onto the entire surface of the aero-casing using the mathematical formulations from [25]. The distortion and residual stresses from the heat treatment model have been mapped onto the surface-hardening process as initial conditions as well. 


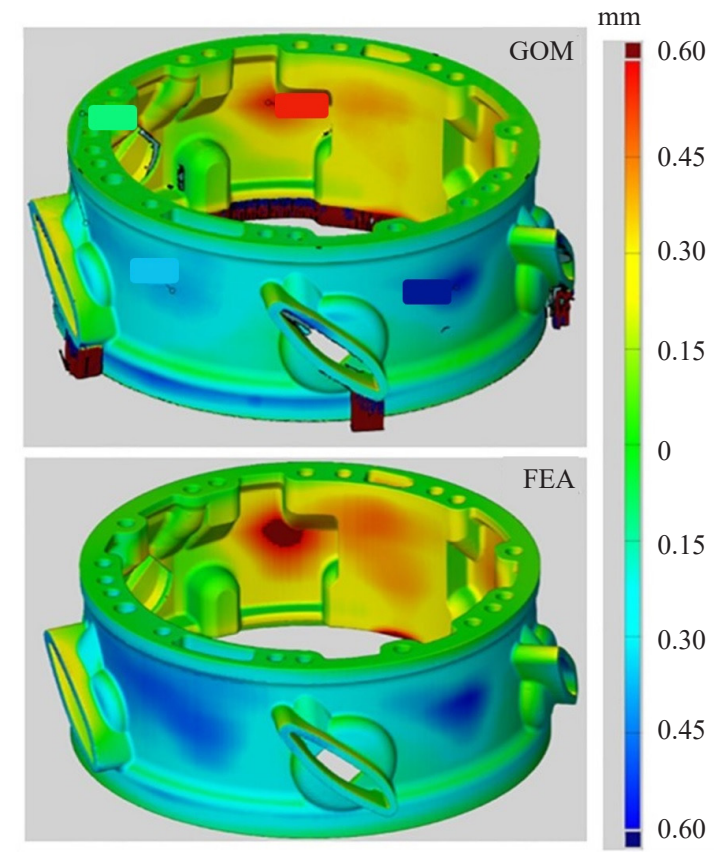

Figure 3. Comparison of measured (GOM) and predicted (FEA) surface deviations [3]

The evolution of the residual stresses is shown in Figure 4. It can be seen that compressive and tensile stresses are generated during the L-PBF. The stresses in the heat treatment have been reduced to less than 50 MPa. The SP and LSP processes have induced compressive residual stresses at the surfaces. The predicted residual stresses in the L-PBF process chain have been used for the prediction of the S-N curves using the endurance limit approach.

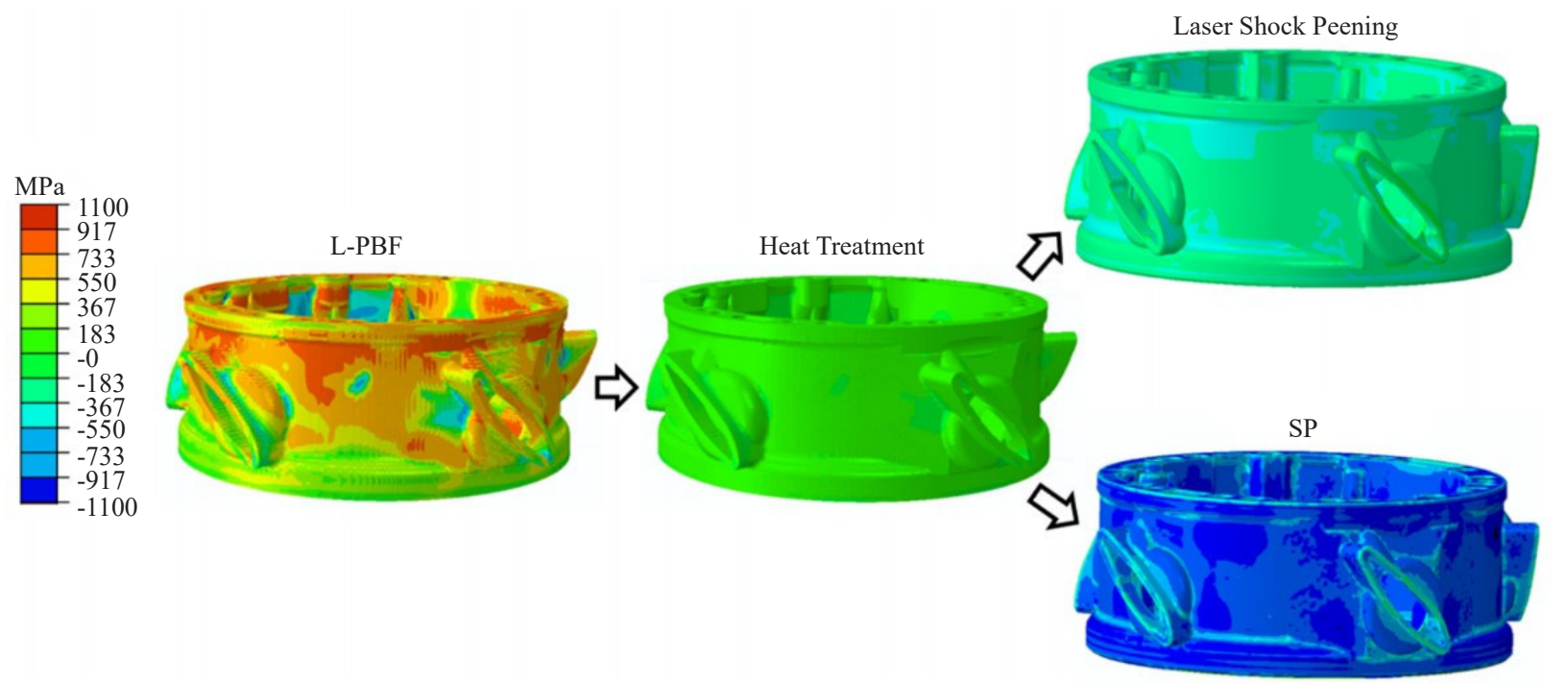

Figure 4. Predicted principal residual stresses in the L-PBF process chain [3] 


\subsubsection{Case studies of an impeller}

Similar to the aero-casing manufacturing process chain, O'Brien et al. [26] simulated a manufacturing process chain of an impeller. The authors applied individually validated process models for L-PBF, heat treatment, SP and LSP into the manufacturing process chain. Figure 5 depicts the evolution of numerically predicted residual stresses during the manufacturing process chain of the impeller. The results demonstrate the impact that each process has on the stress evolution of the impeller, providing a better understanding of the distortion mechanism as well as the risk of crack formation. For many applications, it is recommended to apply heat treatment to L-PBF components to improve mechanical properties and relax residual stresses. It has been demonstrated how residual stresses induced by L-PBF have been reduced by approximately $75 \%$ by the application of heat treatment. It is not uncommon to see the initiation of micro-cracks during the heating of certain nickel-based alloys. The initiation of cracks is observed when the thermal stress exceeds the ultimate stress for a given temperature. Hence, understanding the evolution of residual stresses during L-PBF manufacture and product development through simulation can lead to fewer physical prototypes and reduced overall cost of production.

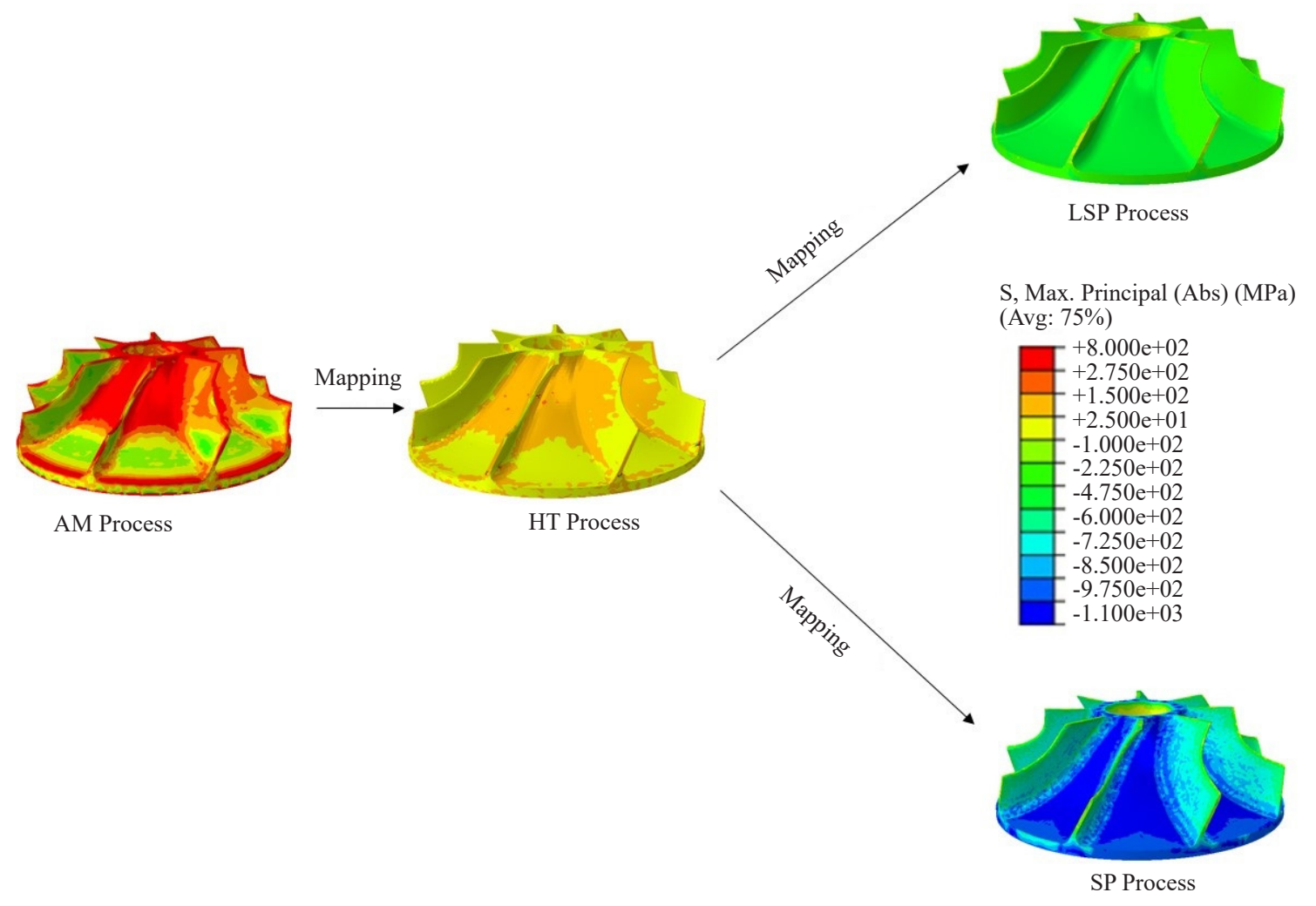

Figure 5. Graphical representation of predicted residual stresses of an impeller [26]

Yaghi et al. [27] predicted the overall distortion and residual stress field of L-PBF followed by post-milling of an industrial impeller made of stainless steel $316 \mathrm{~L}$. They validated the predicted distortions after L-PBF and postmilling. The L-PBF has been modelled using the inherent strain method, while the post-milling has been modelled by deactivating elements from the model and mapping surface-induced stresses from milling using the mapping techniques presented in [3]. They used the predicted distortion to pre-distort the original STL file in the negative direction and produced a final STL file to compensate for the accumulated distortion in the process chain. The final STL file was used to manufacture a new impeller with mitigated holistic distortion as shown in Figure 6. Distortion compensation has 
reduced the overall distortion from around $200 \mu \mathrm{m}$ to around $50 \mu \mathrm{m}$.

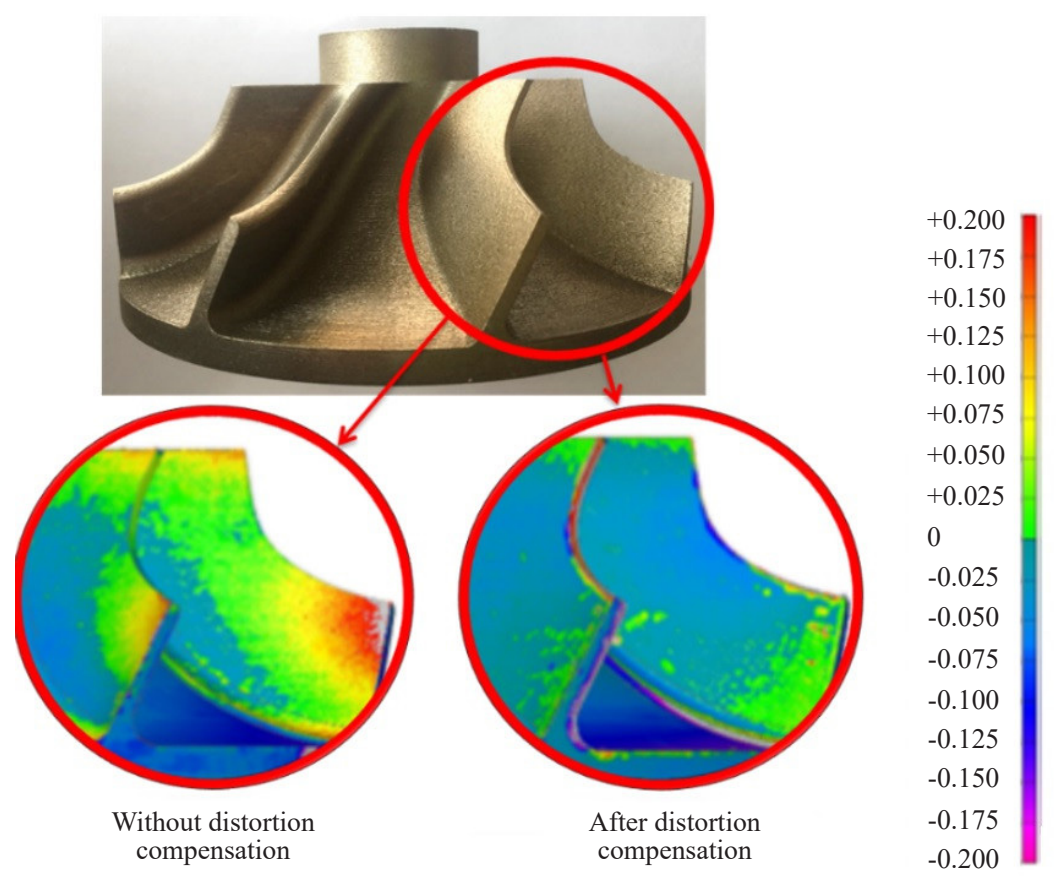

Figure 6. Peak values of the holistic distortion due to L-PBF and post-machining have reduced from around $200 \mu \mathrm{m}$ to around $50 \mu \mathrm{m}[27]$

\section{MSRL tool and industrial implications}

The SimReady tool [4] was used in this study. The readiness level of the tool is analogous to the technology readiness level that has been used in the industry for many years to assess the readiness level of a specific technology. The tool can be applied to the simulation of manufacturing processes to assess the readiness level of the simulation by using a specific simulation software package. The information within the assessment can then be used to establish the current maturity of simulation and to make decisions on whether to adopt the capability to simulate a manufacturing process.

\subsection{The SimReady tool}

The SimReady tool was developed to assess the readiness level of simulation software by considering and assessing the software under seven relevant categories or maturity factors [4]. Within the SimReady tool, a Manufacturing Simulation Readiness Level (MSRL) scale was created to categorise software into distinct groups defined by their use capabilities. The seven maturity factors evolve on a 0-5 scale and are represented in Figure 7 alongside a chart indicating the importance of various activities during the maturation process. 


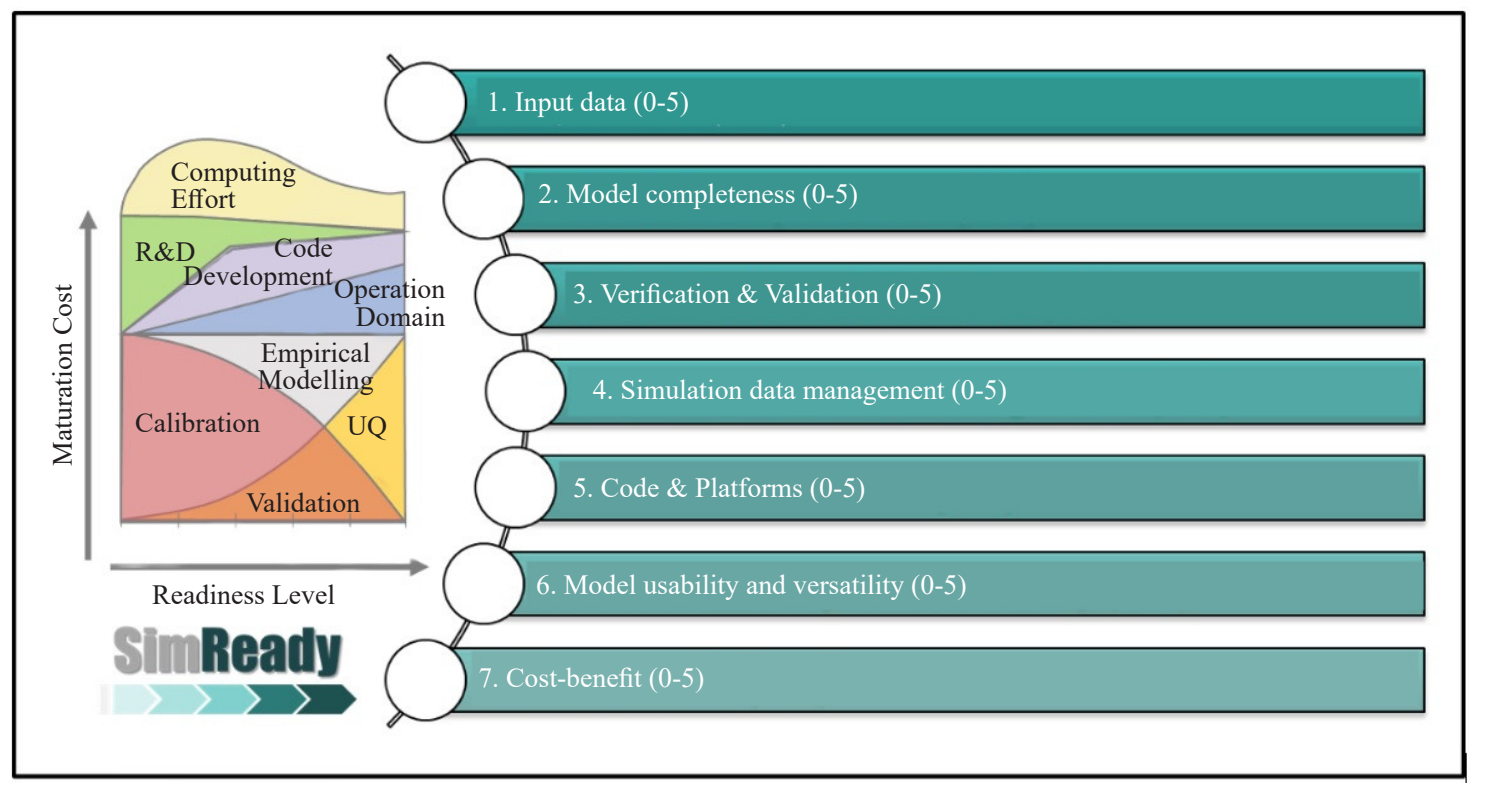

Figure 7. Maturity aspects of SimReady's MSRL

The MSRL scale ranges from level 0 (No Capability Exists) to level 5 (Operational). The levels of MSRL are shown in Figure 8, and are defined as follows:

- MSRL 0 - No Capability Exists: No simulation capability exists in the domain. Prompts identification of research and development (R\&D) needs.

- $\quad$ MSRL 1 - Theoretical R\&D: Conceptual approach; suitable for academic research and concept verification.

- MSRL 2 - Applied R\&D: Feasibility demonstration on a one-off basis on very specific problems, and not as a common practice in the industry. Normally addressed by academia and Research and Technology Organisations (RTOs). Predictive capabilities are suitable for understanding important aspects of the key domain and conceptual feasibility of the engineering design or problem solution.

- MSRL 3 - Instrumental: Supports low-risk development, with high reliance on modelling and simulation experts; normally either outsourced to RTOs or pursued by industrial R\&D departments - normally original equipment manufacturers (OEMs) only. Predictive capabilities are suitable for qualitative assessment, alternative design/solution ranking, defining the design structure, constraining the design space and replacing some experimental trials.

- MSRL 4 - Functional: Modelling and simulation form a functional part of the technology development process for low-mid risk development. Both the model and the simulation codes and platform are highly robust and reliable; usability is sufficient for non-experts. Predictive capabilities are suitable for optimisation and a reduction in experimental trials. Modelling and simulation are part of design best practices, normally performed by internal R\&D departments at OEMs.

- MSRL 5 - Operational: The modelling and simulation methods and codes are well recognised as best practices in the industry and are part of operational process control at any stage of the supply chain. Suitable for virtual engineering, digital product development, robust and optimal product and process design, virtual prototyping, certification and mid to high-risk decisions supported by digital prototypes. 


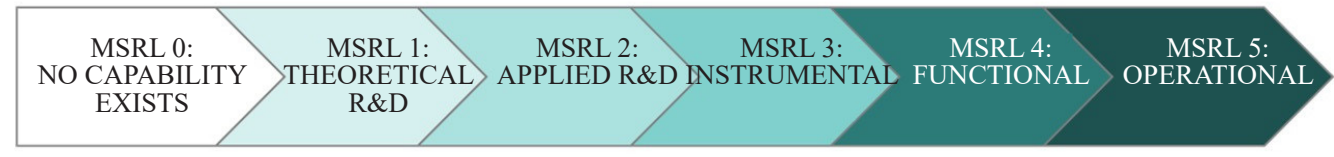

Figure 8. SimReady's MSRL Scale

\subsection{Application of MSRL tool for process chains}

The SimReady tool has been applied to assess the MSRL of the reported process chain. The process chain has been considered collectively to answer the set of questions under each one of the seven maturity factors within the tool. The outcome of the assessment is presented in Figure 9

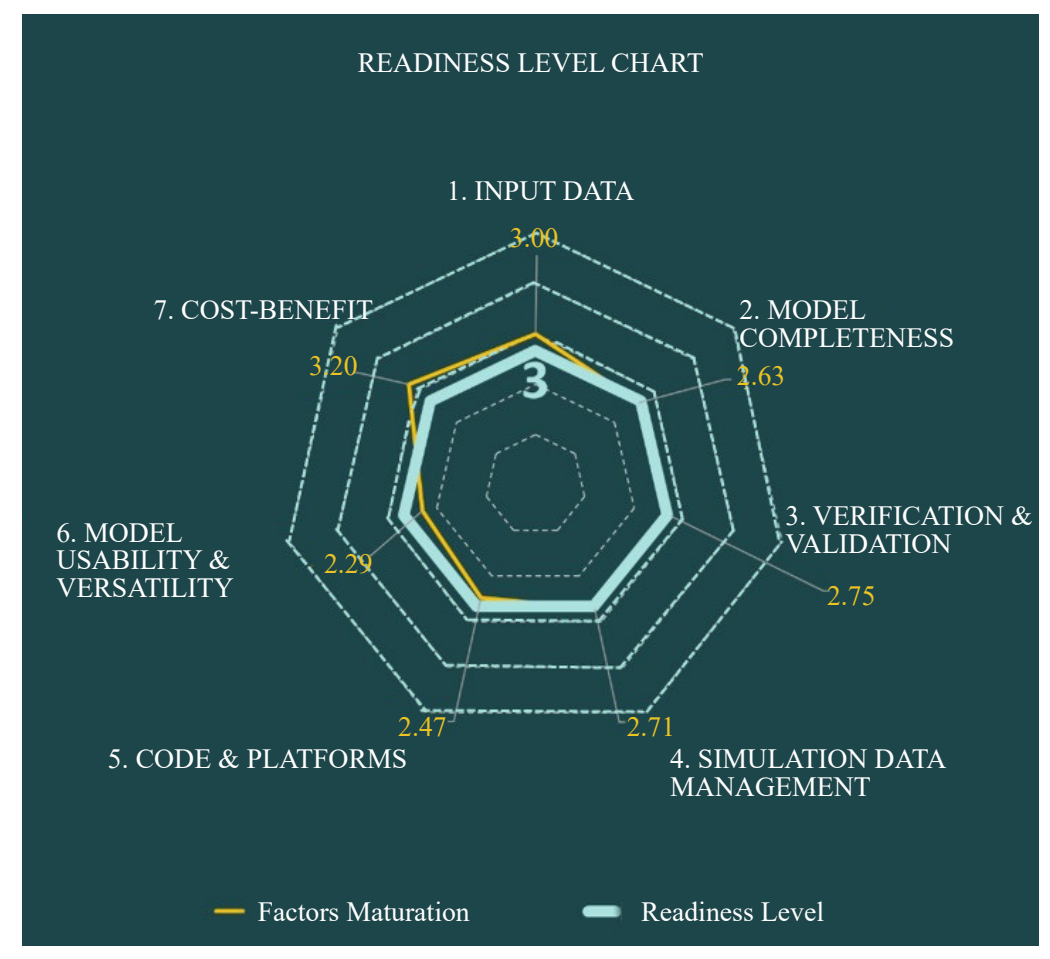

Figure 9. MSRL of the reported L-PBF process chain.

It can be seen from Figure 9 that the overall MSRL score of the reported L-PBF process chain is 3; this has been rounded off from a more accurate score of 2.72, making it lie somewhere between "Applied R\&D" and "Instrumental" as depicted in Figure 8 and described on the page 22. The score of each of the seven maturity factors can also be seen in Figure 9, ranging from a minimum of 2.29 for model usability and suitability, and a maximum of 3.20 for cost-benefit.

The individual scores of the seven maturity factors show the following. The score for Input Data is 3.00, which means that, for example, if the accuracy and reliability of input data were improved, the score could be increased towards 5.00, making the modelling and simulation more robust and reliable, and allowing them to be used for mid to high-risk decisions supported by digital prototypes. The score for Model Completeness is 2.63, which means that it is recommended that different areas of the model are considered carefully, to develop the parts that are not sufficiently developed in order to push the maturity score towards 5.00. The score for Verification \& Validation is 2.75 , indicating that it would be beneficial to invest in making sure that the assumptions and simplifications of the model are realistic, 
valid and accurate, and also making sure that enough validation is carried out with experimental measurement to confirm that the simulation results are correct and sufficiently accurate. The score for Simulation Data Management is 2.71, indicating that investment should be directed towards making processing and presenting the simulation results more standardised and straightforward. The score for Code and Platforms is 2.47 , implying that different parts of the simulation code should be made more robust and accessible and that transferring data between the different platforms should be standardised. The score for Model Suitability \& Usability is 2.29 , which means that it is recommended to examine the model closely in order to improve the applicability of the model under varying conditions within the L-PBF process chain. Finally, the score for Cost-Benefit is 3.20, indicating that, the costs of modelling and simulation should be reduced to improve their maturity; this can be achieved by considering open-source software packages, creating applications (APPs) that can be coded into the model to allow non-expert usage of the model, and establishing ways in which simulation results can substantially reduce the reliability on physical prototypes as part of the design procedure. The above conclusions and recommendations are just examples that may help in increasing the maturity score of the L-PBF process chain modelling and simulation. There can be many other considerations that may also lead to improving the maturation of modelling and simulation of the same process chain.

\subsection{Industrial impact}

The assessment MSRL score of the process chain presented in the previous subsection can be used to make important decisions on the usefulness of adopting simulation to model the mechanical behaviour of the comprising processes. The assessment outcome can be considered carefully to establish the extent to which modelling and simulation can be effectively applied to reduce costs and improve structural integrity. The assessment can also be used to assist in establishing how to take the maturity of the process chain simulation to the next level on the MSRL scale by considering the score of each of the seven maturity factors individually. The information can then help with discussions with decision-makers, improving the chance of adopting modelling and simulation within the manufacturing industrial culture and allowing decisions to be based on quantitative and well-informed arguments.

\section{Concluding remarks}

The numerical simulation of a complete manufacturing process chain for L-PBF has been demonstrated through case studies for raking of metallic powder, L-PBF process and post-processes (i.e. machining, heat treatment, SP and LSP), which was essential to apply the MSRL Tool to conduct a maturity assessment. The results from the assessment showed that the maturity of the L-PBF process chain modelling and simulation is somewhere between the maturity stage of applied research and development and the stage of being instrumental. This means that the L-PBF process chain modelling and simulation are not a common practice in the industry and are normally addressed by academia and Research and Technology Organisations (RTOs). It also means that the L-PBF process chain modelling and simulation can support low-risk development, with high reliance on modelling and simulation experts, making them suitable for qualitative assessment, alternative design/solution ranking, defining the design structure, constraining the design space and replacing some experimental trials. The maturity assessment shows that further maturation is required before the modelling and simulation methods and codes are well recognised as best practice in the industry and are part of operational process control at any stage of the supply chain.

\section{Acknowledgment}

The authors wish to acknowledge Rolls-Royce for allowing the publication of the joint research simulation results presented in subsection 2.1 on the simulation of powder raking. They also wish to acknowledge the High-Value Manufacturing (HVM) Catapult for financially funding most of the remaining work. 


\section{References}

[1] Vock S, Klöden B, Kirchner A, Weibgärber T, Kieback B. Powders for powder bed fusion: a review. Progress in Additive Manufacturing. 2019; 4: 383-397. Available from: doi: 10.1007/s40964-019-00078-6.

[2] Acevedo R, Sedlak P, Kolman R, Fredel M. Residual stress analysis of additive manufacturing of metallic parts using ultrasonic waves: State of the art review. Journal of Materials Research and Technology. 2020; 9(4): 94579477. Available from: doi: 10.1016/j.jmrt.2020.05.092.

[3] Afazov S, Frame J, Ankalkhope U, Bidare P, Liu Y, Vesga W, Dutton B. Prediction of Residual Stress Evolution for End-To-End Process Chain of Laser Powder Bed Fusion Process and Determination of Fatigue SN Curves. In Structural Integrity of Additive Manufactured Materials and Parts, ed. N. Shamsaei and M. Seifi (West Conshohocken, PA: ASTM International, 2020), 165-175. Available from: doi: 10.1520/stp163120190124.

[4] Peavoy D, Matamoros A. Sim Ready - Assessing Manufacturing Modelling \& Simulation Readiness Levels. NAFEMS Benchmark Magazine. 2017; 18-22. Available from: https://www.nafems.org/publications/resource_ center/bm_apr_17_3/. [Accessed January 2021].

[5] Yaghi A, Afazov S, Holloway A, Denmark W. Comparison of Fast Finite Element Modelling Techniques for Prediction of Distortion and Residual Stresses in Laser Powder Bed Fusion. In: Design and Manufacturing Simulation of Additive Manufacturing. NAFEMS Seminar, Coventry, UK. 2017; 1-7. Available from: https://www. researchgate.net/profile/Shukri-Afazov/publication/320307735_COMPARISON_OF_FAST_FINITE_ELEMENT_ MODELLING_TECHNIQUES_FOR_PREDICTION_OF_DISTORTION_AND_RESIDUAL_STRESSES IN_LASER_POWWDER_BED_FÜSION//links/59dcf9e-6a6fdcce237e20b50/COMPARISON-OF-FAST-FINITEELEMENT-MODELLING-TECHNIQUES-FOR-PREDICTION-OF-DISTORTION-AND-RESIDUALSTRESSES-IN-LASER-POWDER-BED-FUSION.pdf. [Accessed January 2021].

[6] Afazov S, Yaghi A, Holloway A, Denmark W, Lazaro-Toralles B, Okioga A. Methodology and Validation of Rapid Prediction of Distortion for Powder-Bed Additive Layer Manufacture. In: NAFEMS World Congress 3rd International Conference on Simulation Process and Data Management. Stockholm, Sweden. 2017; 1-12. Available from: https://www.nafems.org/publications/resource_center/nwc17_806/. [Accessed January 2021].

[7] Afazov S, Denmark W, Lazaro-Toralles B, Holloway A, Yaghi A. Distortion prediction and compensation in selective laser melting. Additive Manufacturing. 2017; 17: 15-22. Available from: doi: 10.1016/ j.addma.2017.07.005.

[8] Roberts IA, Wang CJ, Esterlein R, Stanford M, Mynors DJ. A three-dimensional finite element analysis of the temperature field during laser melting of metal powders in additive layer manufacturing. International Journal of Machine Tools and Manufacture. 2009; 49(12-13): 916-923. Available from: doi: 10.1016/ j.ijmachtools.2009.07.004.

[9] Martukanitz R, Michaleris P, Palmer T, DebRoy T, Liu Z, Otis R, Heo T, Chen L. Toward an integrated computational system for describing the additive manufacturing process for metallic materials. Additive Manufacturing. 2014; 1: 52-63. Available from: doi: 10.1016/j.addma.2014.09.002.

[10] Patil N, Pal D, Rafi H, Zeng K, Moreland A, Hicks A, Beeler D, Stucker B. A Generalized Feed Forward Dynamic Adaptive Mesh Refinement and Derefinement Finite Element Framework for Metal Laser Sintering - Part I: Formulation and Algorithm Development. Journal of Manufacturing Science and Engineering, Transactions of the ASME. 2015; 137(4). Available from: doi: 10.1115/1.4030059.

[11] Deng D, Murakawa H, Liang W. Numerical simulation of welding distortion in large structures. Computer Methods in Applied Mechanics and Engineering. 2007; 196: 4613-4627. Available from: doi: 10.1016/j.cma.2007.05.023.

[12] Huang G, Mehmert P, Schafstall H, Buijk A. On the creation of a new finite element simulation environment for additive manufacturing. In NAFEMS Americas Conference, Session Reviews, Session 7/1D 2016.

[13] Keller N, Ploshikhin V. New method for fast predictions of residual stress and distortion of AM parts. In Solid freeform fabrication symposium 2014 Aug 4 (Vol. 25). Available from: http://utw10945.utweb.utexas.edu/sites/ default/files/2014-096-Keller.pdf. [Accessed January 2021].

[14] Fransen MP. Eigenstrain reconstruction of residual stresses induced by selective laser melting. Master thesis TUDelft, 2016. Report number: 2788. Available from: https://www.researchgate.net/publication/327669628 Eigenstrain_reconstruction_of_residual_stresses_induced_by_selective_laser_melting. [Accessed January 2021].

[15] $\mathrm{Li} \mathrm{C}, \mathrm{Fu}$ C, Guo Y, Fang F. Fast prediction and validation of part distortion in selective laser melting. Procedia Manufacturing. 2015, 1: 355-365. Available from: doi: 10.1016/j.promfg.2015.09.042.

[16] Setien I, Chiumenti M, Van der Veen S, San-Sebastian M, Garciandia F, Echeverria A. Empirical methodology to determine inherent strains in additive manufacturing. Computers \& Mathematics with Applications. 2019; 78: 
2282-2295. Available from: doi: 10.1016/j.camwa.2018.05.015.

[17] Liang X, Cheng L, Chen Q, Yang Q, To AC. A modified method for estimating inherent strains from detailed process simulation for fast residual distortion prediction of single-walled structures fabricated by directed energy deposition. Additive Manufacturing. 2018; 23: 471-486. Available from: doi: 10.1016/j.addma.2018.08.029.

[18] Afazov S, Becker A, Hyde T. Development of a Finite Element Data Exchange System for chain simulation of manufacturing processes. Advances in Engineering Software. 2012; 47: 104-113. Available from: doi: 10.1016/ j.advengsoft.2011.12.011.

[19] Tersing H, Lorentzon J, Francois A, Lundbäck A, Babu B, Barboza J, Bäcker V, Lindgren LE. Simulation of manufacturing chain of a titanium aerospace component with experimental validation. Finite Elements in Analysis and Design. 2012; 51: 10-21. Available from: https://dl.acm.org/doi/abs/10.5555/2745553.2745688. [Accessed January 2021].

[20] Afazov S, Nikov S, Becker A, Hyde T. Manufacturing Chain Simulation of an Aero-engine Disc and Sensitivity Analyses of Micro-scale Residual Stresses. International Journal of Advanced Manufacturing Technology. 2011; 52: 279-290. Available from: doi: 10.1007/s00170-010-2707-2.

[21] Afazov S. Modelling and simulation of manufacturing process chains. CIRP Journal of Manufacturing Science and Technology. 2013; 6: 70-77. Available from: doi: 10.1016/j.cirpj.2012.10.005.

[22] Strondl A, Lyckfeldt O, Brodin H, Ackelid U. Characterization and control of powder properties for additive manufacturing. JOM. 2015; 67(3): 549-554. Available from: doi: 10.1007/s11837-015-1304-0.

[23] Benson J, Snyders E. The need for powder characterisation in the additive manufacturing industry and the establishment of a national facility. South African Journal of Industrial Engineering. 2015; 26(2): $104-114$. Available from: http://www.scielo.org.za/scielo.php?script=sci_arttext\&pid=S2224-78902015000200010\&lng=en \&nrm=iso. [Accessed January 2021].

[24] Matuttis H, Chen J. Understanding the Discrete Element Method: Simulation of Non-Spherical Particles for Granular and Multi-body Systems. Wiley, 2014.

[25] Afazov S, Becker A, Hyde T. Mathematical Modeling and Implementation of Residual Stress Mapping From Microscale to Macroscale Finite Element Models. Journal of Manufacturing Science and Engineering. 2012; 1: 134(2). Available from: doi: doi.org/10.1115/1.4006090.

[26] O’Brien J, Montgomery S, Yaghi A, Afazov S. Process Chain Simulation of Laser Powder Bed Fusion including Heat Treatment and Surface Hardening. CIRP Journal of Manufacturing Science and Technology. 2021; 32: 266276. Available from: doi: 10.1016/j.cirpj.2021.01.006.

[27] Yaghi A, Ayvar-Soberanis S, Moturu S, Bilkhu R, Afazov S. Design against Distortion for Additive Manufacturing. Additive Manufacturing. 2019; 27: 224-235. Available from: doi: 10.1016/j.addma.2019.03.010. 